\title{
Community knowledge, attitudes and practices related to schistosomiasis and associated healthcare-seeking behaviours in northern Côte d'Ivoire and southern Mauritania
}

\author{
Amoin Jeanne d'Arc Koffi ${ }^{1,2}$, Mohamed Doumbia ${ }^{1,3^{*}}$ (D), Gilbert Fokou ${ }^{1}$, Moussa Keita ${ }^{4}$, Brama Koné ${ }^{1,5}$ \\ and N'doumy Noel Abé ${ }^{2}$
}

\begin{abstract}
Background: Among parasitic infections, schistosomiasis ranks second after malaria in terms of worldwide morbidity. Despite efforts to contain transmission, more than 230 million people are infected, of which 85\% live in Sub-Saharan Africa. While the epidemiologic characteristics of schistosomiasis have been extensively studied across endemic settings, social factors have been paid less attention. The current study assesses community knowledge of schistosomiasis causes, transmission, signs, symptoms and prevention, as well as healthcare-seeking behaviours in two West African settings, with the aim of strengthening schistosomiasis control interventions.

Methods: From August 2014 to June 2015, we conducted two cross-sectional surveys in Korhogo, Côte d'Ivoire and Kaédi, Mauritania. We applied a questionnaire to collect quantitative data at the household level in Korhogo $(n=1456)$ and Kaédi $(n=1453$ ). Focus group discussions (Korhogo: $n=32$, Kaédi: $n=32$ ) and participatory photography (photovoice) (Korhogo: $n=16$, Kaédi: $n=16$ ) were conducted within the communities to gather qualitative data. In addition, semi-structured interviews were used to discuss with key informants from control programmes, nongovernmental organizations and health districts (Korhogo: $n=8$, Kaédi: $n=7$ ).

Results: The study demonstrated that schistosomiasis is not well known by the communities; $64.1 \%$ claimed to know the causes of the disease, but the reality is different. This knowledge is more from cultural than biomedical source. It was observed that social construction of the disease is different from the biomedical definition. In Korhogo, schistosomiasis was often associated with several other diseases, notably stomach ulcer and gonorrhoea. The populations believe that schistosomiasis is caused by exposure to goat or dog urine in the environment. In Kaédi, schistosomiasis is considered as a disease transmitted by environmenal elements such as sunshine and dirty water. In both settings, the care-seeking pathways were found to be strongly influenced by local customs and self-medication acquired from the informal sector.

\footnotetext{
*Correspondence: doumess2003@yahoo.fr

'Department of Research and Development, Centre Suisse de Recherches

Scientifiques en Côte d'Ivoire, Abidjan, Côte d'Ivoire

${ }^{3}$ Ethno-Sociology Institute, University Félix Houphouët-Boigny, Abidjan, Côte

d'Ivoire

Full list of author information is available at the end of the article
}

(c) The Author(s). 2018, corrected publication [08/2018]. Open Access This article is distributed under the terms of the Creative Commons Attribution 4.0 International License (http://creativecommons.org/licenses/by/4.0/), which permits unrestricted use, distribution, and reproduction in any medium, provided you give appropriate credit to the original author(s) and the source, provide a link to the Creative Commons license, and indicate if changes were made. The Creative Commons Public Domain Dedication waiver (http://creativecommons.org/publicdomain/zero/1.0/) applies to the data made available in this article, unless otherwise stated. 
(Continued from previous page)

Conclusions: This study revealed that knowledge about the aetiology, transmission, symptoms, prevention and treatment of schistosomiasis among the populations in Korhogo and Kaédi is based on their local culture. Deep-rooted habits could therefore pose a significant obstacle to the elimination of schistosomiasis.

Keywords: Community knowledge, Healthcare-seeking behaviour, Schistosomiasis, Korhogo, Kaédi, Côte d'Ivoire, Mauritania

\section{Multilingual abstracts}

Please see Additional file 1 for translations of the abstract into the six official working languages of the United Nations.

\section{Background}

In terms of global morbidity, schistosomiasis is the most devastating parasitic disease after malaria. More than 200 million people are currently at risk of contracting schistosomiasis across the globe, $85 \%$ of whom live in Africa [1, 2]. In 2016, about 89.2 million individuals have received chemotherapy treatment [3]. It is estimated that across 74 endemic countries the number of annual deaths caused by the disease could be as high as 200000 [4]. Schistosomiasis, which is caused by different sub-genera of the genus Schistosoma - a blood fluke - is responsible for nearly 3.31 million disability-adjusted life years (DALYs) due to anaemia as a result of haematuria, and bladder, kidney, liver and spleen disease $[5,6]$.

WHO current control strategy of schistosomiasis is based on preventive chemotherapy by periodic administration of the antischistosomal drug praziquantel, particularly, to school age children, considered as high-risk group, alongside with vector control [7]. Although praziquantel reduces morbidity and might impact on transmission, it rarely eliminates infection $[8,9]$.

Schistosomiasis is an important health concern in West Africa. In Côte d'Ivoire, where it is a major cause of disability and ill health [10], its prevalence ranges from less than $1 \%$ to more than $50 \%$ depending on the locality [11]. The north of the country has a mean prevalence close to $30 \%$. In Mauritania, transmission of schistosomiasis primarily occurs in the south and south-east, with prevalence rates ranging from 1.3 to $90 \%[12,13]$. To counteract the persistence of the disease, both the Côte d'Ivoire and Mauritania governments distribute praziquantel and albendazole. The strategy is structured around the involvement of various levels of the health pyramid (i.e. control program, health districts and community health centres). To optimise the disease control practice, health agents are being trained by the national control program in both countries to implement the control protocol more effectively $[14,15]$.

Despite the widespread prevalence and efforts to contain the disease, it seems that populations of both countries know little about schistosomiasis [16] and health-seeking behaviours are often directed towards traditional methods [17]. Only a few studies have targeted the topic of community knowledge and sub-optimal health-seeking behaviours regarding schistosomiasis epidemiology $[16,17]$. However, there is a significant body of evidence that suggests that human behaviours can increase or decrease the risk of schistosomiasis infection [18].

This study aims to assess community knowledge, attitudes and practices (KAP) linked to schistosomiasis in Korhogo, Côte d'Ivoire and Kaédi, Mauritania, in order to determine the impact of knowledge on healthcare-seeking behaviours.

\section{Methods}

\section{Study area and population}

The study was conducted in Korhogo, northern Côte d'Ivoire, and Kaédi, south Mauritania. The choice of those settings is justified by: (i) their respective locations in the southern and northern part of the Sahel band; (ii) Korhogo and Kaédi respectively being located in semi-arid and arid settings, near water bodies (Senegal River for Kaédi and Bandama River for Korhogo); and (iii) the livelihoods of the inhabitants being centred on agriculture, fishing and livestock keeping.

Korhogo is located at $09^{\circ} 27^{\prime} 41^{\prime \prime} \mathrm{N}$ and $05^{\circ} 38^{\prime} 19^{\prime \prime} \mathrm{W}$, and it is the main town of the Poro region. The population of Korhogo town was estimated at 258699 inhabitants in 2014 [19]. The local ethnic group is constituted principally of Sénoufo from the voltaic cultural area. The hydrographical network is dominated by the Bandama River and its tributaries. The annual mean rainfall ranges from 1200 to $1500 \mathrm{~mm}$. The vegetation of the area is west Sudanian Savanna, according to the classification of ecoregions as defined by the World Wide Fund for Nature.

Kaédi is located at $6^{\circ} 09^{\prime} 02^{\prime \prime} \mathrm{N}$ and $13^{\circ} 30^{\prime} 20^{\prime \prime} \mathrm{W}$ at the bank of the Senegal River. It is the main town of the Gorgol region, with a (no census data available) population estimated at 121000 inhabitants in 2013 [20, 21]. The Kaédi population is composed of several ethnic groups, namely Halpulaar, Moors, Soninké and Wolof. The mean annual rainfall is 300 to $500 \mathrm{~mm}$ and the vegetation is of the Sahelo-Sudanese type. From the livelihood activities carried out including agriculture and 
fishing, Kaédi appears to be the main breadbasket of Mauritania (see Fig. 1).

\section{Study procedures}

Two cross-sectional surveys were conducted in each setting, one during the dry season and one during the rainy season. Prior to the study's inception, both administrative and local authorities were informed about the study's aims, procedures, benefits and eventual risks. The study was designed combining qualitative and quantitative approaches. Data collected with qualitative methods (i.e. observations and interviews) were triangulated with household questionnaires and literature review.

For the quantitative approach, 1456 and 1453 households were sampled in Korhogo and Kaédi, respectively. The survey team used a questionnaire and visited each selected household unit to collect data on KAP pertaining to schistosomiasis. The household head or his representative was interviewed by investigators who were trained in data collecting techniques in order to reduce biases.

For the qualitative approach, 32 focus group discussions (FGDs) were conducted in each community, 16 participatory photography exercises (photovoice) and 15 semi-structured interviews were also conducted in both countries (8 in Korhogo and 7 in Kaédi) either with community members or key informants from the national control program, non-governmental organisations (NGOs) and health districts. Data collection was conducted in the local languages with support from local trained field assistants. The survey was conducted in the Senoufo language in Korhogo (the most widely spoken language in the area), while Pulaar and Hassania arabic, the most popular languages of the Gorgol region, were alternatively used for data collection in Kaédi. Any potential bias was reduced by training the assistants for two days on basic concepts and notions related to the study and data collection methodology. The responses were firstly recorded in local languages and then translated into French during systematic transcription using Microsoft Word 2013 (Microsoft Corporation, Redmond, WA, USA).

The FGDs were conducted separately for different sex and age groups, resulting in four groups constituted of young men, young women, adult men and adult women. Potential participants were screened for eligibility. The selected ones were those who have lived in the community at least six months prior to the interview to avoid selection bias. Male and female participants aged 18-35 were selected for the age category of 'young' and those aged from 36 were selected for the age category of 'adult'. The choice of these categories was motivated by the fact that perceptions at the community level vary according to social positions and status that are basically defined by age and sex. Participants must have also lived in the study area for more than six months prior to the start of the survey and able to communicate in the local language. At the community level, permission was obtained from the local authorities following a briefing on the study. A contact person who facilitated the introduction to the village and assisted in mobilising each category was chosen by the community leader. The number of participants in each focus group varied from seven to 10 for each of the four groups per study site. For each study site, 16 FGDs were conducted during each season (rainy and dry) resulting in a total of 32 FDGs per site.

Participatory photography or photovoice consisted of 16 community members taking photographic images in each study location. Selected individuals in some households were given a disposable camera and asked to take
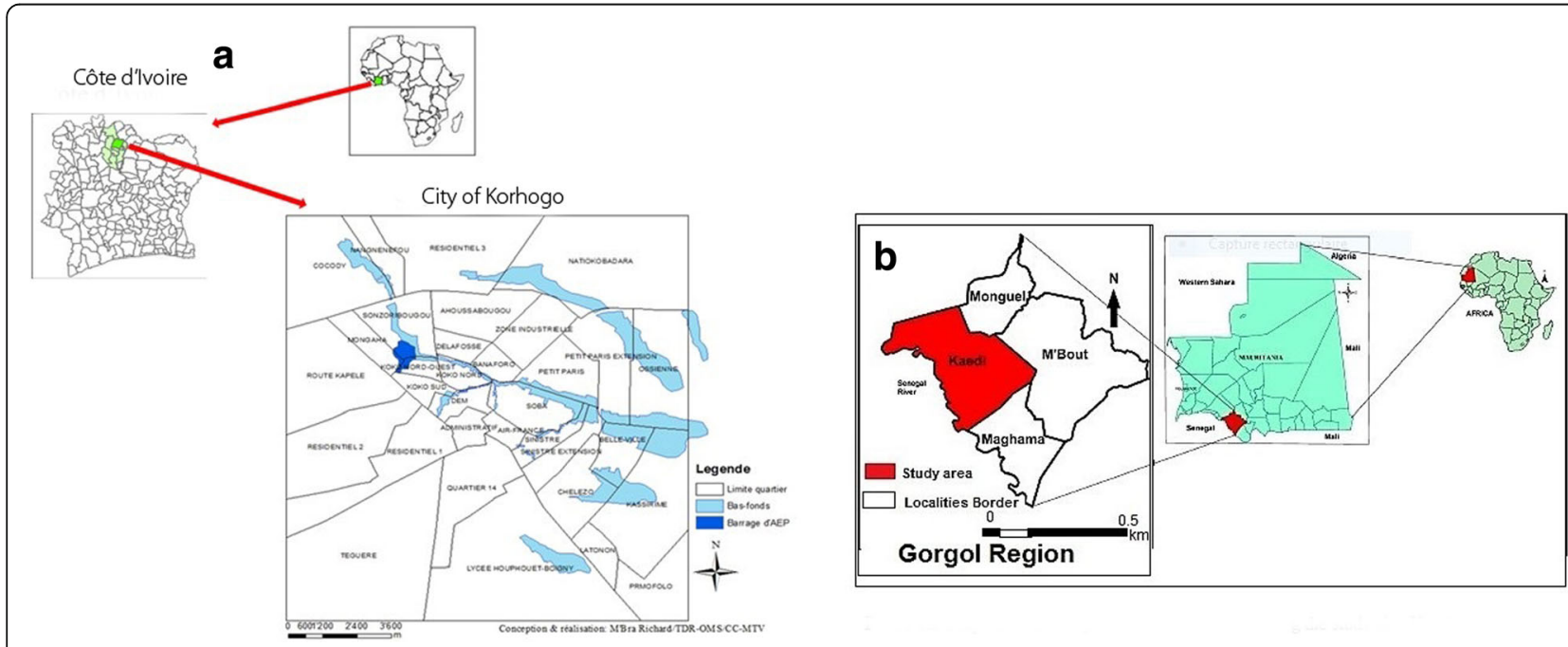

Fig. 1 a: Map of Republic of Côte d'Ivoire, showing the study site, Korhogo. b: Map of Islamic Republic of Mauritania, showing the study site, Kaedi 
photos of everything they thought was related to schistosomiasis. It was explained to them that the photographs should be made in strict respect of people's privacy and that the images should not allow for the recognition of individuals or their property. Photographers were then interviewed individually and collectively about the content and meaning of their photos, as well as the messages they wanted to convey through the photos. This was done following an interview protocol summarised under the acronym SHOWeD: 'what we See - what is Happening - relation to Our lives - Why does this exist - what to Do about it' [22]. Photos were then analysed individually and collectively to understand the knowledge of communities related to schistosomiasis and the strategies put in place to control the disease.

Semi-structured interviews were also conducted with individual key informants both in the population and in health facilities, using an interview guide, with the aim of noting down not only the habits and ideologies of the populations, but also evaluating the local policies and care and control strategies. The key persons involved were health facility workers, municipal and traditional authorities, and local development NGOs.

\section{Sample size}

The questionnaire for eliciting complementary quantitative data was applied in 1456 households in Korhogo and 1453 in Kaédi. The number of households was selected randomly from each town. The sample size $N$ was calculated using the following formula $[21,23]$ :

$\left.N=\delta^{\wedge} 2 \times p(1-p) \times \mathrm{c}\right) / \mathrm{i}^{\wedge} 2$,

where $\delta=1.96, P=0.35$, expected prevalence of schistosomiasis; $\mathrm{c}=2$, correction factor; and $i=0.05$, margin of error.

\section{Data analyses}

Quantitative data were entered into EpiData version 3.5.3 (The EpiData Association, Odense, Denmark) and analysed using SPSS version 18 (IBM Corp, Chicago, USA). General community knowledge of schistosomiasis and healthcare-seeking behaviours regarding schistosomiasis were analysed and expressed in proportions. The chi-square test and Fisher's exact test were used to show correlations between variables.

Qualitative data were processed using MaxQDA version 12 (VERBI GmbH, Berlin, Germany). Data recorded during interviews were systematically transcribed into Microsoft Word (Microsoft Corporation, Redmond, WA, USA). Information on transcribed text was then grouped according to pre-established codes based on the interview guide and key covariates used for the study. After the first coding, data were recoded for further content analysis.

\section{Results}

Socio-demographic characteristics of informants

The proportion of male to female respondents was 45.5 to $54.5 \%$ in Kaédi and 45.5 to $54.5 \%$ in Korhogo, respectively. A significant number of participants were living under monogamous marriage regime $(65.6 \%$ in Kaédi and $49.1 \%$ in Korhogo), and most were Muslims (98\% in Kaédi and $71.5 \%$ in Korhogo). The majority of the participants worked in the informal sector comprising traders, artisans, farmers, herdsmen and intermediaries (62.3\% in Kaédi and 68.4\% in Korhogo). About a third of the respondents in both sites have never received any formal education (32.7\% Kaédi and 39.8\% Korhogo). About a third of respondents from Kaédi (32.6\%) have received Arabic education in Coranic school, while about a quarter in Korhogo had a secondary school level of education (23.7\%) (Additional file 2: Table S1 summarizes the socio-demographic characteristic).

\section{Knowledge of schistosomiasis Local names of schistosomiasis}

The local names of schistosomiasis in Korhogo and Kaédi are summarized in Table 1 . The identified entities with respect to schistosomiasis were different from one site to another. In Korhogo, four different names for schistosomiasis were reported - linked to the urogenital system and gastrointestinal tract. Two of the local names, 'sonfichichan' and 'firmaning', designate urinary pain; 'sonfichichan' refers to the pain during urination, while 'firmaning' is translated as the 'root of urine'. Thus, any infection related to the genital tract and any disease that pertains to sex is referred to as the 'root of urine'. However, after the clinical signs of schistosomiasis were described to the participants, it became clear that 'firmaning' was not directly related to the infection but referred to the inflammation of the prostate or gonorrhoea.

Intestinal schistosomiasis is often confused with dysentery, that is named 'lagbồ in Senoufo and 'tôtônou', a name borrowed from their Malinké neighbours (Malinké are a neighbouring ethnic group to the Senoufo in north Côte d'Ivoire sharing the same livelihood activities and habits). These two expressions are descriptive of diarrhoea with blood and mucus in the stool, that is meant to describe dysentery. However, owing to the similarity of symptoms between both diseases and a lack of information, these two terms are also applied to describe schistosomiasis.

In Kaédi, there is a single name to designate schistosomiasis among each ethnic group. Participants were able to provide some of the local names from the community that were associated with symptoms and causes of schistosomiasis. The Halpulaar use the word 'boobri' for the disease while the Moors call it 'issri bolt'. These local names referred to elements of the natural environment, such as water and sun, for both ethnic groups. 
Table 1 Local names for schistosomiasis according to locality and ethnic group

\begin{tabular}{|c|c|c|c|}
\hline Ethnic group & Type of schistosomiasis & Local name & Meaning of local name \\
\hline \multicolumn{4}{|l|}{ Korhogo } \\
\hline \multirow[t]{4}{*}{ Senufo } & Black schistosomiasis & Firmaning & Schistosomiasis due to a curse (pain during urination, blood after urination) \\
\hline & White schistosomiasis & Firmaning & Schistosomiasis due to a contact with an infected person \\
\hline & & Sonfichichan & Difficulty to urinate \\
\hline & Intestinal schistosomiasis & Tôtônou or lagbô & Another form of white schistosomiasis (pain during urination) \\
\hline Malinké & Intestinal schistosomiasis & Tôtônou & Glow in stool \\
\hline \multicolumn{4}{|l|}{ Kaédi } \\
\hline \multirow[t]{2}{*}{ Halpulaar } & Black schistosomiasis & Boobri balleri & Schistosomiasis due to water \\
\hline & White schistosomiasis & Boobri doneri & Schistosomiasis due to heat \\
\hline \multirow[t]{3}{*}{ Moors } & White schistosomiasis & Issri lébiane & Schistosomiasis due to heat \\
\hline & Black schistosomiasis & Issri lékal & Schistosomiasis due to urination on someone's else urine \\
\hline & Pain during urination & Issri bolt & Schistosomiasis due to heat \\
\hline
\end{tabular}

According to both groups, schistosomiasis can be contracted through water or sun, thus there is a name to designate schistosomiasis that is contracted by sun and another by water. Among the Moors, it is believed that one can contract schistosomiasis by urinating on someone's else urine. In both groups, schistosomiasis due to water was perceived as the most complicated.

\section{Social aetiology of schistosomiasis}

In general, the causes of schistosomiasis mentioned by the study participants varied between the study sites and ethnic groups. From the Senufo's perspective, the disease is linked to the environment and to mysticism. In relation to the environment, it is believed that there are several transmission routes: (i) stepping on urine from goats or dogs; (ii) drinking unsafe water or playing in dirty water; and (iii) using dirty and defected toilets. This last point was illustrated in Korhogo, where a participant described one infection route as follows:

'I have been a victim of schistosomiasis we are talking about. One can contract it in the toilet. For example, if you urinate where someone who is infected has just urinated, you can be contaminated.' (FGD with adult women, Korhogo, April 2015).

According to this perspective, a lack of hygiene and sanitation is considered as an enabling factor for the occurrence of schistosomiasis. However, mystic causalities are also blamed. They are referred to in particular when a violation of social rules is involved, such as committing adultery. According to a traditional healer:

'When men commit adultery, this can cast a curse on them. They are going to get infected.' (Interview with a traditional healer, Korhogo, April 2015).
In Kaédi, two causes for schistosomiasis were identified: environmental causes and natural causes. According to Halpulaar, schistosomiasis is transmitted through water contact during activities related to water, or when consuming either unsafe water or water heated by the sun. The Halpulaars link the disease to water because their village was formerly surrounded by water and the disease was rampant. Thus, they have been told that water was the cause of the disease. Among the natural causes, the Moors believe that schistosomiasis is caused by sunrays and by walking barefoot on hot sand.

\section{Knowledge of disease symptoms}

Knowledge of the symptoms and manifestations of schistosomiasis is summarized in Table 2. Overall, $82.7 \%$ of respondents identified the disease by blood in urine, $34.9 \%$ by low urine output and $33.6 \%$ by pain during urination. The most commonly mentioned symptom across both settings was blood in urine $(70.6 \%$ in Korhogo and $86.6 \%$ in Kaédi) and pain during urination $(29.4 \%$ in Korhogo and $34.9 \%$ in Kaédi). Low urine output was mentioned more often in Kaédi as compared with Korhogo (44.0\% versus $7.0 \%$, respectively).

It was found that in Korhogo the level of education is not associated to the knowledge of schistosomiasis symptoms (see Table 3). However, in Kaédi the level of education seemed to be relevant for the identification of symptoms such as low urine output and frequent urination $(65.0 \%$ of responses, $P=0.001)$. However, symptoms such as pain during urination seemed to be more known by people who had a higher level of education (43.0\% of responses). Blood in urine was a well-known symptom by all respondents regardless of their level of education in both localities (>70.0\%). 
Table 2 Knowledge of schistosomiasis symptoms according to locality*

\begin{tabular}{|c|c|c|c|c|c|c|}
\hline & \multicolumn{2}{|l|}{$\begin{array}{l}\text { Kaédi } \\
n=503\end{array}$} & \multicolumn{2}{|c|}{$\begin{array}{l}\text { Korhogo } \\
n=195\end{array}$} & \multicolumn{2}{|l|}{$\begin{array}{l}\text { Total } \\
n=698\end{array}$} \\
\hline & Yes $(n)$ & Yes (\%) & Yes $(n)$ & Yes (\%) & Yes $(n)$ & Yes $(\%$ \\
\hline Do you know about schistosomiasis symptoms? & 441 & 87.7 & 143 & 73.3 & 584 & 83.7 \\
\hline Pain during urination & 154 & 34.9 & 42 & 29.4 & 196 & 33.6 \\
\hline Low urine output & 194 & 44.0 & 10 & 7.0 & 204 & 34.9 \\
\hline Blood in stool & 204 & 46.3 & 72 & 50.3 & 276 & 47.3 \\
\hline Stomach pain & 93 & 21.1 & 8 & 5.6 & 101 & 17.3 \\
\hline Headache & 61 & 13.8 & 7 & 4.9 & 68 & 11.6 \\
\hline Blood in urine & 382 & 86.6 & 101 & 70.6 & 483 & 82.7 \\
\hline${ }^{\mathrm{a} O}$ Other symptoms & 14 & 3.2 & 25 & 17.5 & 39 & 6.7 \\
\hline
\end{tabular}

*Multiple choice question; ${ }^{a}$ Wound on genitals, constipation; $n$ : Number of respondents

\section{Knowledge of transmission pathways}

Regarding schistosomiasis transmission, 63.8 and $65.1 \%$ of participants in Kaédi and Korhogo, respectively, affirmed knowing the route (see Table 4). However, $62.5 \%$ of respondents in Kaédi and $37.9 \%$ in Korhogo stated that drinking unsafe water transmits schistosomiasis. Furthermore, contact with dirty water was mentioned as a source of infection (50.7\% in Kaédi and $43.1 \%$ in Korhogo). Swimming was cited as another way of becoming infected by schistosomiasis $(59.1 \%$ in Kaédi and $65.3 \%$ in Korhogo). In fact, in Kaédi, knowledge of schistosomiasis transmission pathway is linked to education level. For instance, swimming in the river is more cited by educated people compared to non-educated ones $(P<0.001)$ etc. (see Table 5$)$.

During the FGDs, behaviours such as drinking unsafe water, swimming and walking under the sun were mentioned as risk factors for infection.

\section{Knowledge of prevention measures}

In Kaédi, among the respondents who were aware of schistosomiasis, less than half cited at least one effective protective measure (see Table 6). Only 30\% of all the

Table 3 Population's knowledge of schistosomiasis symptoms according to level of literacy in Korhogo and Kaédi

\begin{tabular}{|c|c|c|c|c|c|c|}
\hline & No education (\%) & Arabic (\%) & Primary (\%) & Secondary (\%) & High school (\%) & $P$-value \\
\hline Korhogo & $n=576$ & $n=155$ & $n=263$ & $n=343$ & $n=107$ & \\
\hline Knowledge of schistosomiasis & $54(9.4)$ & $17(11)$ & 49 (18.6) & 106 (30.6) & $45(42.1)$ & $\leq 0.001^{\mathrm{a}}$ \\
\hline Knowledge of symptom ${ }^{d}$ & $23(42.6)$ & $11(64.7)$ & $24(49.0)$ & $54(50.9)$ & $29(64.4)$ & $0.856^{\mathrm{a}}$ \\
\hline Pain during urination & $9(39.1)$ & $6(54.4)$ & $9(37.5)$ & $14(24.6)$ & $4(0.05)$ & $0.5^{\mathrm{b}}$ \\
\hline Low urine output & $3(13.0)$ & $1(9.1)$ & $3(12.5)$ & $3(5.3)$ & $0(0.0)$ & N/A \\
\hline Blood in stool & $11(47.8)$ & $4(36.4)$ & $8(33.3)$ & $31(54.4)$ & $16(55.2)$ & $0.384^{\mathrm{a}}$ \\
\hline Stomach pain & $0(0.0)$ & $1(9.1)$ & $2(8.2)$ & $3(5.3)$ & $1(3.4)$ & N/A \\
\hline Headache & $0(0.0)$ & $0(0.0)$ & $1(4.2)$ & $4(7.0)$ & $2(6.9)$ & N/A \\
\hline Blood in urine & $11(47.8)$ & $9(81.8)$ & $19(79.2)$ & $39(68.4)$ & $22(75.9)$ & $0.111^{\mathrm{a}}$ \\
\hline${ }^{\mathrm{C} O t h e r ~ s y m p t o m s ~}$ & $7(30.4)$ & $2(18.2)$ & $1(4.2)$ & $8(14.0)$ & $7(24.1)$ & $0.135^{b}$ \\
\hline Kaédi & $n=473$ & $n=472$ & $n=236$ & $n=195$ & $n=72$ & \\
\hline Knowledge of schistosomiasis & $276(58.4)$ & $228(48.3)$ & $122(51.7)$ & $107(54.9)$ & $35(48.6)$ & $0.031^{\mathrm{a}}$ \\
\hline Knowledge of symptom ${ }^{d}$ & $170(61.6)$ & $114(50.0)$ & $67(54.9)$ & $66(61.7)$ & $23(65.7)$ & $0.441^{\mathrm{a}}$ \\
\hline Pain during urination & $52(30.6)$ & $49(43.0)$ & $24(35.8)$ & $18(27.3)$ & $10(43.5)$ & $0.129^{\mathrm{a}}$ \\
\hline Low urine output & $66(38.8)$ & $65(57.0)$ & $26(38.8)$ & $21(31.8)$ & $15(65.2)$ & $0.001^{\mathrm{a}}$ \\
\hline Blood in stool & $76(44.7)$ & $56(49.1)$ & $29(43.3)$ & $29(43.9)$ & $13(56.5)$ & $0.755^{\mathrm{a}}$ \\
\hline Stomach pain & $35(20.6)$ & $30(26.3)$ & $12(17.9)$ & $8(12.1)$ & $7(30.4)$ & $0.151^{a}$ \\
\hline Headache & $28(16.5)$ & $22(19.3)$ & $6(9.0)$ & $2(3.0)$ & $3(13.0)$ & $0.020^{\mathrm{b}}$ \\
\hline Blood in urine & $144(84.7)$ & $98(86.0)$ & $61(91.0)$ & $61(92.4)$ & $17(73.9)$ & $0.146^{\mathrm{a}}$ \\
\hline${ }^{c}$ Other symptoms & $8(4.7)$ & $3(2.6)$ & $3(4.5)$ & $0(0.0)$ & $0(0.0)$ & N/A \\
\hline
\end{tabular}


Table 4 Knowledge of transmission pathway of schistosomiasis according to locality*

\begin{tabular}{|c|c|c|c|c|c|c|}
\hline & \multicolumn{2}{|l|}{$\begin{array}{l}\text { Kaédi } \\
n=779\end{array}$} & \multicolumn{2}{|c|}{$\begin{array}{l}\text { Korhogo } \\
n=289\end{array}$} & \multicolumn{2}{|c|}{$\begin{array}{l}\text { Total } \\
n=1068\end{array}$} \\
\hline & Yes $(n)$ & Yes (\%) & Yes $(n)$ & Yes (\%) & Yes $(n)$ & Yes (\%) \\
\hline Do you know how schistosomiasis is transmitted? & 497 & 63.8 & 188 & 65.1 & 685 & 64.1 \\
\hline Drinking unsafe water & 312 & 62.8 & 72 & 38.3 & 384 & 56.1 \\
\hline Eating poorly washed fruits, vegetables & 81 & 16.3 & 5 & 2.7 & 86 & 12.6 \\
\hline Swimming in rivers, drains, etc. & 295 & 59.4 & 124 & 66.0 & 419 & 61.2 \\
\hline Contact with infected person & 41 & 8.2 & 15 & 8.0 & 56 & 8.2 \\
\hline Walking barefoot on infected urine & 110 & 22.1 & 13 & 6.9 & 123 & 18.0 \\
\hline Contact with dirty water & 253 & 50.9 & 81 & 43.1 & 334 & 48.8 \\
\hline${ }^{a}$ Other transmission & 38 & 7.6 & 22 & 11.7 & 60 & 8.8 \\
\hline Do not know & 6 & 1.2 & 2 & 1.1 & 8 & 1.2 \\
\hline
\end{tabular}

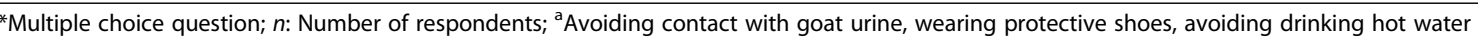

respondents $(n=1450)$ stated that they knew what the preventive behaviours for schistosomiasis are. In Korhogo, respondents cited that avoiding swimming is a unique effective preventive measure (76.3\%).

Table 7 summarizes the participants' knowledge of preventive means for schistosomiasis control. In Korhogo, the level of education was found to be correlated with the knowledge of the control measure, such as swimming. The frequencies of responses were higher in the highest educated groups compared with the lowest educated groups $(78.8-88.2 \%$ versus $42.9-47.8 \% ; P<0.001)$. Other risk factors, such as avoiding urinating and defecating in water, were little known, regardless of a person's education level. The impact of the education level on the knowledge of prevention measures in Korhogo was weak or not clearly demonstrated. In Kaédi, among the prevention measures, avoiding drinking unsafe water and avoiding swimming were often mentioned. In fact, $77.0 \%$ of non-educated people and $50.0 \%$ of educated respondents mentioned that drinking unsafe water should be avoided.

Table 5 Knowledge of transmission pathways of schistosomiasis according to level of literacy in Korhogo and Kaédi*

\begin{tabular}{|c|c|c|c|c|c|c|}
\hline & No education (\%) & Arabic (\%) & Primary (\%) & Secondary (\%) & High school (\%) & $P$-value \\
\hline Korhogo & $n=26$ & $n=13$ & $n=33$ & $n=75$ & $n=38$ & \\
\hline Drinking unsafe water & $8(29.6)$ & $5(38.5)$ & $11(34.4)$ & $32(42.1)$ & $15(39.5)$ & $0.817^{b}$ \\
\hline Eating poorly washed fruits, vegetables & $1(3.7)$ & $1(7.7)$ & $0(0.0)$ & $2(2.6)$ & $1(2.6)$ & N/A \\
\hline Swimming in rivers, drains, etc. & $11(40.7)$ & $7(53.8)$ & $25(78.1)$ & $51(67.1)$ & $26(68.4)$ & $0.035^{\mathrm{a}}$ \\
\hline Contact with infected person & $4(14.8)$ & $3(23.1)$ & $1(3.1)$ & $4(5.3)$ & $1(2.6)$ & N/A \\
\hline Walking barefoot on infected urine & $3(11.1)$ & $1(7.7)$ & $1(3.1)$ & $8(10.59)$ & N/A & $0.217^{b}$ \\
\hline Contact with dirty water & $11(40.7)$ & $9(69.2)$ & $10(31.3)$ & $35(46.1)$ & $15(39.5)$ & $0.200^{\mathrm{a}}$ \\
\hline${ }^{\mathrm{c}}$ Other & $6(22.2)$ & $2(15.4)$ & $2(6.3)$ & $10(13.2)$ & $2(5.3)$ & $0.230^{\mathrm{b}}$ \\
\hline Do not know & $1(3.7)$ & $0(0.0)$ & $0(0.0)$ & $0(0.0)$ & $1(2.6)$ & N/A \\
\hline Kaédi & $n=189$ & $n=136$ & $n=86$ & $n=76$ & $n=27$ & \\
\hline Drinking unsafe water & $137(72.5)$ & $76(60.3)$ & $44(55.0)$ & $36(47.4)$ & $18(66.7)$ & $0.001^{\mathrm{a}}$ \\
\hline Eating poorly washed fruits, vegetables & $26(13.8)$ & $29(23.0)$ & $13(16.3)$ & $7(9.2)$ & $6(22.2)$ & $0.073^{\mathrm{a}}$ \\
\hline Swimming in rivers, drains, etc. & $79(41.8)$ & $82(65.1)$ & $56(70.0)$ & $59(77.6)$ & $18(66.7)$ & $<0.001^{\mathrm{a}}$ \\
\hline Contact with infected person & $9(4.8)$ & $13(10.3)$ & $9(11.3)$ & $5(6.6)$ & $5(19.2)$ & $0.058^{\mathrm{a}}$ \\
\hline Walking barefoot on infected urine & $45(23.8)$ & $31(24.6)$ & $13(16.3)$ & $9(11.8)$ & $12(44.4)$ & $0.005^{a}$ \\
\hline Contact with dirty water & $85(45.0)$ & $73(57.9)$ & $42(52.5)$ & $36(47.4)$ & $16(59.3)$ & $0.175^{a}$ \\
\hline${ }^{\mathrm{C}}$ Other & $17(9.0)$ & $13(10.3)$ & $3(3.8)$ & $3(3.9)$ & $2(7.4)$ & $0.291^{\mathrm{b}}$ \\
\hline Do not know & $3(1.6)$ & $1(0.8)$ & $0(0.0)$ & $2(2.6)$ & $0(0.0)$ & N/A \\
\hline
\end{tabular}

*Multiple choice question; Statistically significant $P$-values $(<0.05)$ are highlighted in bold $n$ : Number of respondents; ${ }^{\mathrm{a}} P$-value based on chi-square test; ${ }^{\mathrm{b}} P$-value based on Fisher's exact test; ${ }^{\mathrm{c}}$ Contact with goat urine, not wearing protective shoes, drinking hot water, exposure to sunlight 
Table 6 Knowledge of schistosomiasis prevention measures according to locality*

\begin{tabular}{|c|c|c|c|c|c|c|}
\hline & \multicolumn{2}{|c|}{$\begin{array}{l}\text { Kaédi } \\
n=1450\end{array}$} & \multicolumn{2}{|c|}{$\begin{array}{l}\text { Korhogo } \\
n=1443\end{array}$} & \multicolumn{2}{|l|}{$\begin{array}{l}\text { Total } \\
n=2893\end{array}$} \\
\hline & Yes $(n)$ & Yes (\%) & Yes $(n)$ & Yes (\%) & Yes $(n)$ & Yes (\%) \\
\hline Do you know how to avoid schistosomiasis? & 438 & 30.2 & 173 & 12.0 & 611 & 21.1 \\
\hline Avoid eating certain foods & 77 & 17.6 & 4 & 2.3 & 81 & 13.3 \\
\hline Avoid drinking unsafe water & 285 & 65.1 & 86 & 49.7 & 371 & 60.7 \\
\hline Avoid swimming in rivers, drains, etc. & 214 & 48.9 & 132 & 76.3 & 346 & 56.6 \\
\hline Avoid urinating in water bodies & 198 & 45.2 & 37 & 21.4 & 235 & 38.5 \\
\hline Avoid defecating in water bodies & 201 & 45.9 & 31 & 17.9 & 232 & 38.0 \\
\hline${ }^{\mathrm{a} O}$ Other & 25 & 5.7 & 24 & 13.9 & 49 & 8.0 \\
\hline Do not know & 6 & 1.4 & 2 & 1.2 & 8 & 1.3 \\
\hline
\end{tabular}

*Multiple choice question; $n$ : Number of respondents; ${ }^{a}$ Avoid contact with goat urine, wear protective shoes, avoid drinking hot water

$58.3 \%$ of respondents with a higher education mentioned avoiding swimming as a protective measure compared with $31.0 \%$ of the non-educated individuals $(P<0.001)$.

The choice of prevention measures depends on people's perceptions with regards to the disease. In fact, the Halpulaar believe that not consuming unsafe water makes it possible to avoid schistosomiasis. The Moors believe that the disease is preventable by no exposure to sunrays. They recommend that:

'to avoid the disease (schistosomiasis), one should not drink dirty water or water that has been heated by the sun' (FGD with women, Kaédi, June 2015).
It appears that, the local populations have poor knowledge of prevention means.

\section{Impact of knowledge of the disease on healthcare- seeking behaviours}

Care practices varied among ethnic groups. It appeared that the communities' knowledge of the disease socially constructs people's care-seeking choices. Praziquantel is an effective treatment against all human forms of schistosomiasis. However, according to the populations' knowledge of the disease, their healthcare-seeking behaviours differ from curative solutions proposed by medical science.

Table 7 Knowledge of schistosomiasis prevention measures according to level of literacy in Korhogo and Kaédi*

\begin{tabular}{|c|c|c|c|c|c|c|}
\hline & No education (\%) & Arabic (\%) & Primary (\%) & Secondary (\%) & High school (\%) & $P$-value \\
\hline Korhogo & $n=23$ & $n=14$ & $n=34$ & $n=68$ & $n=33$ & \\
\hline Avoid eating certain foods & $0(0.0)$ & $2(14.3)$ & $1(2.9)$ & $1(1.5)$ & $0(0.0)$ & N/A \\
\hline Avoid drinking unsafe water & $9(39.1)$ & $5(35.7)$ & $16(47.1)$ & $39(57.4)$ & $16(48.5)$ & $0.430^{\mathrm{b}}$ \\
\hline Avoid swimming in rivers, drains, etc. & $11(47.8)$ & $6(42.9)$ & $27(79.4)$ & $60(88.2)$ & $26(78.8)$ & $<0.001^{a}$ \\
\hline Avoid urinating in water bodies & $6(26.1)$ & $4(28.6)$ & $3(8.8)$ & $17(25.0)$ & $6(18.2)$ & $0.319^{b}$ \\
\hline Avoid defecating in water bodies & $3(13.0)$ & $1(7.1)$ & $2(5.9)$ & $18(26.5)$ & $6(18.2)$ & $0.079^{b}$ \\
\hline${ }^{\mathrm{a}}$ Other & $5(21.7)$ & $5(35.7)$ & $3(8.8)$ & $7(10.3)$ & $4(12.1)$ & $0.082^{b}$ \\
\hline Do not know & $0(0.0)$ & $0(0.0)$ & $0(0.0)$ & $2(2.9)$ & $0(0.0)$ & $\mathrm{N} / \mathrm{A}$ \\
\hline Kaédi & $n=174$ & $n=106$ & $n=63$ & $n=72$ & $n=24$ & \\
\hline Avoid eating certain foods & $30(17.2)$ & $25(23.6)$ & $11(17.5)$ & $5(6.9)$ & $6(25.0)$ & $0.056^{b}$ \\
\hline Avoid drinking unsafe water & $135(77.6)$ & $63(59.4)$ & $35(55.6)$ & $36(50.7)$ & $16(66.7)$ & $<0.001^{a}$ \\
\hline Avoid swimming in rivers, drains, etc. & $54(31.0)$ & $58(54.7)$ & $38(60.3)$ & $50(70.4)$ & $14(58.3)$ & $<0.001^{\mathrm{a}}$ \\
\hline Avoid urinating in water bodies & $76(43.7)$ & $60(56.6)$ & $24(38.1)$ & $26(36.6)$ & $12(50.0)$ & $0.053^{\mathrm{a}}$ \\
\hline Avoid defecating in water bodies & $77(44.3)$ & $60(56.6)$ & $25(39.7)$ & $27(38.0)$ & $12(50.0)$ & $0.092^{\mathrm{a}}$ \\
\hline${ }^{\mathrm{C}}$ Other & $8(4.6)$ & $8(7.5)$ & $5(7.9)$ & $2(2.8)$ & $2(8.3)$ & $0.548^{b}$ \\
\hline Do not know & $2(1.2)$ & $2(1.9)$ & $2(3.2)$ & $0(0.0)$ & $0(0.0)$ & N/A \\
\hline
\end{tabular}

*Multiple choice question; Statistically significant $P$-values $(<0.05)$ are highlighted in bold

$n$ : number of respondents; ${ }^{a} P$-value based on chi-square test; ${ }^{b} P$-value based on Fisher's exact test; ${ }^{c}$ avoiding contact with goat urine, wearing protective shoes, avoiding drinking hot water 
In Korhogo, respondents believe there are two kinds of schistosomiasis: natural and mystic. The natural form as designated by community is the same as the one defined by biomedical medicine, and is also acquired through walking on goat or dog urine. However, the mystic form is believed to be contracted through witchcraft. Care-seeking behaviours depend on those perceptions. In Kaédi, the population recognises the natural form of schistosomiasis. However, the perception around the transmission pathway (i.e. exposure to sunlight, drinking hot water) influences care-seeking behaviours and leads to the use of inappropriate ways of protection.

\section{Treating the natural form of schistosomiasis}

To treat the natural form, people rely firstly on self-medication, local customs and drugs sourced from the informal sector (e.g. street markets). Going to the hospital appears to be the last resort. A local custom involves a stone being heated, which the patient crouches over, and the heat that emerges from it goes towards the genitals and cures the disease. Beyond this practice, communities self-medicate often using a black powder of unknown composition or a capsule commonly called 'toupaille' that is mixed with a soft drink, both of which are sold in the informal sector.

It appears that cultural conceptions of schistosomiasis influence health-seeking behaviours, as evidenced by the following statement:

'Schistosomiasis is rare, so we do not know how to treat ourselves.' (FGD with adult women, Korhogo, April 2015).

In addition, various avenues for seeking treatment were pointed out including: traditional healers, hospitals and street healers. An adult female participant stated:

'I was once suffering from schistosomiasis, so I did the indigenous treatment. It did not work, then I went to the American dispensary. They examined me, they took my urine and they found it was this disease. So they gave me a treatment that I took, and then I was also given an appointment, so when I went back there, they gave me the rest of the medication and I was cured.' (FGD with adult women, Koko, Korhogo, April 2015).

Participants agreed that they do not know the effective treatment. One stated:

'One of my nieces has been infected with this disease. So really, we did everything, it did not work, there's black powder medicine there, at home. They used that, it did not work.' (FDG with young women, Korhogo, April 2015).

\section{Treating the mystic form of schistosomiasis}

According to participants, the mystic form of schistosomiasis can only be treated by traditional healers through prayers and medicinal plants. In Kaédi, most participants agreed that schistosomiasis is curable. One avenue for seeking treatment that was pointed out by both ethnic groups was domestic processes. Care is strongly based upon self-medication: Moors use 'hénné": bathing with cold water to lower the body temperature. According to the respondents, schistosomiasis is present when the body is hot because of exposure to sunrays. They believe that the heat generated by the sun is accumulated in the lower abdomen and the burning causes schistosomiasis.

The Halpulaar use a powder made from a tree called 'tékié. This powder is mixed with water or milk and ingested as a therapeutic drink. They also use a plant called 'N'nan' for treatment, which is also mixed with milk.

Data from both sites revealed that there is no effective means to prevent schistosomiasis and, at the household level, there are no particular practices to control schistosomiasis.

\section{Discussion}

Regardless of locality, study participants had similar levels of KAP relating to schistosomiasis control. However, it seems that communities in Kaédi had more knowledge about schistosomiasis signs and symptoms compared with their counterparts in Korhogo.

Generally, the results around people's knowledge in both settings are in line with those from studies conducted in Ethiopia, Ghana and Côte d'Ivoire; these focused on perceptions of the general population and found low levels of knowledge about the disease even in endemic areas [17, 21, 24]. However studies in other schistosomiasis-endemic areas have found a general high level of awareness of schistosomiasis. A study conducted in Zimbabwe, for instance, reported that $80 \%$ of people in villages were aware of schistosomiasis [25]. Similarly, a study conducted in Brazil revealed that people were fairly familiar with schistosomiasis [26]. Findings from a study in Kenya also showed that schistosomiasis is known by populations, but its recognition as a major health concern is still limited among the communities assessed [23]. The low level of knowledge in Korhogo and Kaédi regarding schistosomiasis is explained by changes in environmental conditions (relocation, building of agricultural dams). In Korhogo, the building of dams in recent years for agricultural and pastoral 
activities throughout the seasons has contributed to rapidly changing environmental conditions, what has increased schistosomiasis prevalence [27]. In Kaédi, the Moors ethnic group did not link the epidemiology of schistosomiasis to water contact because they originate from an area of Mauritania where access to water is limited. Even among those who have moved to new residential places near water points (Senegal River) generations ago, the level of knowledge of the disease has not increased. In addition, the lack of sensitisation concerning the disease contributed to the communities' ignorance, thus making them vulnerable to the disease $[28,29]$.

A variety of local names designate schistosomiasis disease, such as 'sonfichichan', 'firmaning' (also used for gonorrhoea) and 'lagbô' (intestinal schistosomiasis). The disease is often confused with dysentery or stomach ulcer in Korhogo. In fact, a study conducted by Acka and colleagues in the endemic area of Man in western Côte d'Ivoire in 2010 highlighted the confusion concerning the designation of the disease [17]. In Kaédi, 'boobri' and 'issri bolt' mean urinary schistosomiasis among the Halpulaar and Moors, respectively. Local names connote the disease's signs and symptoms. The concept of naming a disease through signs and symptoms was also reported by Biays and colleagues in Cambodia where people used a variety of names to designate schistosomiasis in the Khmer language; 'santéas omal' means 'the disease of the big bellies'; 'dam ksir' translates word by word as 'crab pipe' and refers to abdominal pains like the sensation of crab claws. The expression 'tleak andaek' illustrates splenomegaly by the 'falling turtle' in the abdomen, while 'teach tuk' ('water in the belly') is the name given to ascites [30].

In general, the proportion of respondents who mentioned different disease symptoms in Kaédi was higher compared with those in Korhogo. This could be explained by the fact that people in Kaédi have closer contact with the river in their daily activities. In line, a recent study conducted in Kaédi by Gbalégba and colleagues identified 12 types of water contact activities that populations living close to the dam take part in, including swimming/bathing $(n=3788,36.9 \%)$; washing clothes $(n=2016,19.7 \%)$; and washing dishes $(n=1322,12.9 \%)$ [31].

The knowledge of the aetiology of schistosomiasis is influenced by socio-cultural beliefs. In the current study, populations in both localities did not know the transmission pathway well. Data also show that the education level has no influence on the respondents' knowledge in Korhogo. In fact, the knowledge of disease aetiology was related to drinking unsafe water, environmental factors (sun and unsafe water), and mysticism. Drinking unsafe water was perceived to be the major cause of infection [32]. The respondents argued that unsafe drinking water or practising lugubrious activities, as well as exposure to sunrays, leads to infection. The study furthermore shows that being contaminated with urine of animals such dogs and goats is perceived as a being the main source of transmission. This perception might be due to the low transmission levels of the disease in the study areas. Nonetheless, a study conducted in an endemic zone of schistosomiasis transmission in Niger [29] revealed that the community's ignorance of the disease put it at a higher risk of infection. It appears that living in an endemic area is not a sufficient condition for knowing pathology.

In Kaédi, the aetiology of the disease was unknown, while the symptoms of the urinary form were well known. This variation of schistosomiasis knowledge was also observed in a study done in Nampula province, Mozambique [28], where the community knew the symptoms of schistosomiasis but lacked the knowledge on the causes, putting them in a position of vulnerability. The lack of knowledge of the aetiology observed in Korhogo and Kaédi could be attributable to the absence of sensitisation activities in both localities. In fact, a study conducted in Niger demonstrated that at the beginning of the study schistosomiasis was little known, but that participants' knowledge improved moderately after one year of sensitisation [29]. Hence, health education may be an important means of improving individual recognition of the disease [33].

The study also showed that knowledge of prevention measures was low and that a person's education level impacts weakly on this knowledge. In Kaédi, the education level influenced the knowledge of schistosomiasis prevention measures. In fact, the social construction of people, i.e., how people perceive the transmission of the disease in their socio-cultural context appeared to be important factors of exposure to infection. Thus, knowledge of prevention measures is influenced by knowledge of disease causes. The study also showed that in Korhogo the population did not use any schistosomiasis prevention strategies. It is therefore clear that a lack of knowledge of schistosomiasis in general influences the choice of treatment and, more importantly, people's attitude to the disease. In Yemen, it was observed that a lack of knowledge of the disease influenced the knowledge of prevention means. In Sri Lanka, care-seeking behaviours of mothers and maternal knowledge of symptoms contributed to reducing childhood disease [34]. Hence, the lack of knowledge of prevention measures exposes individuals to a risk of infection. In addition, the respondents mentioned that the 'risky' way they live in connection with their immediate environment prevents them to protect themselves against schistosomiasis. The same finding has been reported elsewhere. Communities around Lake Victoria in Uganda and Kenya, for instance, know how to avoid the disease, but they state that there is nothing they can do due to their dependency on water 
for domestic and economic use [35, 36]. In line with a lack of knowledge concerning prevention means, previous studies in Brazil and Egypt have also demonstrated that avoiding drinking unsafe water is perceived as an effective means to prevent infection [32, 37].

Our work furthermore shows that care practices varied between ethnic groups. The knowledge of the disease and the social construction around it influences people's care-seeking choices. This leads to people using methods that are in contrast to those advocated by biomedical sciences and which may result in a delay in effective healthcare. The same result has been found by Mandelzweig and colleagues who show that perceptual, social and behavioural factors contribute to a delay in seeking medical care in acute ischemic cases [38]. Along the same lines, many authors argue that health beliefs are important barriers to care seeking [34, 39, 40].

It was found that using various herbal remedies to treat schistosomiasis is practised by people in both communities. However, this often prevents people from seeking medical treatment [41]. The absence of good care practices is reflected in the fact that communities often do not know that there are medical means to manage the disease. Beyond this, there are environmental and social factors that influence the search for care. This observation was made by MacKian in his study on health systems. He showed that social, environmental and economic factors influence communities' healthcare-seeking behaviours [42]. The lack of knowledge due to a weak prevalence of schistosomiasis in both study sites leads to communities relying on means that maintain and aggravate the disease [43]. However, a study conducted in the Magu district of Tanzania observed that in endemic areas patients refer to traditional healers as a care-seeking behaviour [44]. As it is noticed that people did not know the disease, their seeking treatment pathway totally differed from the biomedical's, hence they were in a position of vulnerability with regards to schistosomiasis.

\section{Conclusions}

This study aimed to add to the limited literature exploring KAP related to schistosomiasis control at the community and household levels. The study showed that schistosomiasis is poorly known in both West African settings assessed. It was found that communities tended to rely on traditional cures, and that persisting misconceptions pose barriers to effective disease prevention and control. In addition, there is little knowledge on how to prevent schistosomiasis and the causes of disease. It is therefore important to sensitise communities about schistosomiasis treatment and its efficacy. Policymakers and health organisations should contribute to improve knowledge at the individual and community levels. This could be made possible through a participative or integrated approach to the disease by combining treatments with community health education at the grassroots level.

\section{Additional files}

Additional file 1: Multilingual abstracts in the six official working languages of the United Nations. (PDF $591 \mathrm{~kb}$ )

Additional file 2: Table S1. Sociodemographic characteristics of informants. (DOC $58 \mathrm{~kb}$ )

\section{Abbreviations}

FGD: Focus group discussion; KAP: Knowledge, attitudes and practices; NGO: Non-governmental organisation

\section{Acknowledgments}

The authors are grateful to all IDRC/WHO staff members who supported this study, and all the respondents and participants who willingly gave their time to respond to the questionnaire. We thank Dr. Jasmina Saric, from the Swiss Tropical and Public Health Institute (STPH), and Drs Jean T. Coulibaly and Richard B. Yapi from the Centre Suisse de Recherches Scientifiques en Côte $d^{\prime}$ Ivoire for their useful review and inputs. We also thank all other team members of the project NB20283 (http://vbd-environment.org/the-5research-projects/project-e/the-team) for their assistance during data collection and comments made during project meetings.

\section{Funding}

This project received financial support from the UNICEF/UNDP/World Bank WHO Special Programme for Research and Training in Tropical Diseases (TDR) and the Canadian International Development Research Centre (IDRC) (grant no. NB20283 to Dr. Brama Koné). The funders had no role in the study design, data collection and analyses, decision to publish, or preparation of the paper.

Availability of data and materials

Please contact the corresponding author for data.

Authors' contributions

Study design: AJAK, BK, MD, GF, NNA. Data collection: AJAK, MD, GF, BK, MK. Data analysis: AJAK. Paper drafting: AJAK. Draft review: GF, MD, BK, NNA.

\section{Authors' information}

AJAK: MSc, Department of Research and Development, Centre Suisse de Recherches Scientifiques en Côte d'Ivoire, Abidjan, Côte d'Ivoire; Environment and Communication training unit, University Alassane Ouattara, Bouaké, Côte d'Ivoire.

MD: PhD, Lecturer, Ethno-Sociology Institute, University Félix HouphouëtBoigny, Abidjan, Côte d'Ivoire.

GF: PhD, Associate Researcher, Department of Research and Development, Centre Suisse de Recherches Scientifiques en Côte d'Ivoire, Abidjan, Côte d'lvoire.

MK: PhD, Lecturer, University of Nouakchott, Nouakchott, Mauritania. BK: PhD, Lecturer, Institute of Agro-pastoral management, University Péléforo-Gbon-Coulibaly, Korhogo, Côte d'Ivoire.

NNA: PhD, Lecturer, Environment and Communicationt training unit, University Alassane Ouattara, Bouaké, Côte d'Ivoire.

\section{Ethics approval and consent to participate}

This study received clearance from the Ministry of Health and Public Hygiene of the Republic of Côte d'Ivoire (N¹0 056/MSLS/CNER-dkn). The scientific committee of the Faculty of Medicine at the University of Nouakchott, acting as a national ethic committee, cleared the research protocol (reference no. 042/ USTM/FM, dated 23 May 2013). In addition, local authorities in Kaédi and Korhogo were informed about the objectives, procedures, benefits and potential risks of the study. Each survey participant signed an informed consent form. Participants were instructed not to mention the names of people or 
places where pictures were taken to maintain confidentiality. Permission was also requested from participants at the beginning of each discussion for using a device to record the discussion or a camera for shooting elements concerning schistosomiasis through photovoice method.

\section{Consent for publication}

Not applicable.

\section{Competing interests}

The authors declare that they have no competing interests.

\section{Author details}

'Department of Research and Development, Centre Suisse de Recherches Scientifiques en Côte d'Ivoire, Abidjan, Côte d'Ivoire. Environment and Communication Training Unit, University Alassane Ouattara, Bouaké, Côte d'Ivoire. ${ }^{3}$ Ethno-Sociology Institute, University Félix Houphouët-Boigny, Abidjan, Côte d'Ivoire. ${ }^{4}$ Faculty of Letters and Social Sciences, University of Nouakchott, Nouakchott, Mauritania. ${ }^{5}$ University Péléforo-Gbon-Coulibaly, Korhogo, Côte d'Ivoire.

Received: 25 September 2017 Accepted: 15 June 2018

Published online: 10 July 2018

\section{References}

1. Vennervald BJ, Dunne DW. Morbidity in schistosomiasis: an update. Curr Opin Infect Dis. 2004;17:439-47.

2. Steinmann P, Keiser J, Bos R, Tanner M, Utzinger J. Schistosomiasis and water resources development: systematic review, meta-analysis, and estimates of people at risk. Lancet Infect Dis. 2006;6:411-25.

3. WHO. Schistosomiasis and soil-transmitted helminthiases: number of people treated in 2015. Wkly Epidemiol Rec. 2016;91:585-600.

4. OMS. Relevé épidémiologique hebdomadaire. OMS; 2016 Dec p. 585-600. Report No.: 91, 49/50.

5. Murray CJL, Vos T, Lozano R, Naghavi M, Flaxman AD, Michaud C, et al. Disability-adjusted life years (DALYs) for 291 diseases and injuries in 21 regions, 1990-2010: a systematic analysis for the global burden of disease study 2010. Lancet. 2012;380:2197-223.

6. Hotez PJ, Alvarado M, Basáñez M-G, Bolliger I, Bourne R, Boussinesq M, et al. The global burden of disease study 2010: interpretation and implications for the neglected tropical diseases. PLoS Negl Trop Dis. 2014;8:e2865.

7. Evan Secor W. Water-based interventions for schistosomiasis control. Pathog Glob Health. 2014;108:246-54.

8. Utzinger J, Zhou XN, Chen MG, Bergquist R. Conquering schistosomiasis in China: the long march. Acta Trop. 2005;96:69-96.

9. Muhumuza S, Kitimbo G, Oryema-Lalobo M, Nuwaha F. Association between socio economic status and schistosomiasis infection in Jinja District, Uganda. Tropical Med Int Health. 2009;14:612-9.

10. Silué KD, Raso G, Yapi A, Vounatsou P, Tanner M, N'Goran EK, et al. Spatiallyexplicit risk profiling of plasmodium falciparum infections at a small scale: a geostatistical modelling approach. Malar J. 2008;7:111.

11. Chammartin F, Houngbedji CA, Hürlimann E, Yapi RB, Silué KD, Soro G, et al. Bayesian risk mapping and model-based estimation of Schistosoma haematobium-Schistosoma mansoni co-distribution in Côte d' Ivoire. PLoS Negl Trop Dis. 2014;8:e3407.

12. Ouldabdallahi M, Ouldbezeid M, Diop C, Dem E, Lassana K. Épidémiologie des bilharzioses humaines en Mauritanie. L'exemple de la rive droite du fleuve Sénégal. Bull Société Pathol Exot. 2010;103:317-22.

13. Ould ASC, Alassane MT. Prevalence and parasite load of urinary schistosomiasis in schoolchildren in the Wilaya of Gorgol in Mauritania. Med Trop Rev Corps Sante Colon. 2011;71:261-3.

14. Traye BG. Rapport des activités du troisième trimestre 2014. Abidjan, Côte d'Ivoire: Programme National de lutte contre les Géohelminthes, les schistosomiases et la Filariose Lymphatique; 2014 p. 5-18.

15. Ministère de la santé Rapport de l'enquête sur la cartographie des maladies négligées en Mauritanie. Mauritanie: Programme national de lutte contre les Bilharziose/MTN; 2015 p. 25.

16. Abé NN. Contribution of socio-anthropology in Schistosomiasis controlTAABO/Côte d'Ivoire experiment. J Homeopaty. 2014:3:1-5.

17. Acka AC, Raso G, N'goran EK, Tschannen AB, Bogoch I, Essan S. Parasitic worms: knowledge, attitudes, and practices in western Côte d'Ivoire with implications for integrated control. PLoS Negl Trop Dis. 2010:e910.
18. Chippaux J-P. La lutte contre les schistosomoses en Afrique de I'Ouest. IRD Editions; 2000.

19. RGPH. Résultats RGPH. 2014:2014. Available from: www.ins.ci/n/documents/ Population_des_communes.pdf.

20. RGHP 2013. Projections Démographiques Mauritanie 2015 · Répartition_ spatiale. [Internet]. [cited 2017 May 6]. Available from: http://www.ons.mr/ index.php/publications/operations-statistiques/16-rgph-2013.

21. Legesse $M$, Jones $C R$, Singh SK, Erko B, Mekonnen Y. Community's awareness about intestinal schistosomiasis and the prevalence of infection in two endemic localities of Ethiopia. Ethiop J Health Sci. 2009;19:133-48

22. Wang CA. Participatory action research strategy applied to Women's health. J Women's Health. 1999;8:185-92.

23. Musuva RM, Awiti A, Omedo M, Ogutu M, Secor WE, Montgomery SP, et al. Community knowledge, attitudes and practices on schistosomiasis in western Kenya-the SCORE project. Am J Trop Med Hyg. 2014;90:646-52.

24. Yirenya-Tawiah DR, Annang T, Otchere J, Bentum D, Edoh D, Amoah C, et al. Urinary schistosomiasis among adults in the Volta Basin of Ghana: prevalence. knowledge and practices J Trop Med Parasitol. 2011;34:1-16.

25. Ndamba J, Makura O, Gwatirisa PR, Makaza N. Kaondera KC. A cost effective two step rapid diagnosis of urinary schistosomiasis in Zimbabwe. Cent Afr J Med. 1998:44:167-71.

26. Uchoa E, Barreto SM, Firmo JO, Guerra HL, Pimenta FG, MFFL e C. The control of schistosomiasis in Brazil: an ethno-epidemiological study of the effectiveness of a community mobilization program for health education. Soc Sci Med. 2000;51:1529-41.

27. N'goran EK, Diabate S, Utzinger J, Sellin B. Changes in human schistosomiasis levels after the construction of two large hydroelectric dams in central Côte d'Ivoire. Bull World Health Organ. 1997;75:541.

28. Rassi C, Kajungu D, Martin S, Arroz J, Tallant J, de Beyl CZ, et al. Have you heard of schistosomiasis? Knowledge, attitudes and practices in Nampula Province, Mozambique. PLoS Negl Trop Dis. 2016;10:e0004504.

29. Garba A, Aboubacar A, Barkire A, Vera C, Sellin B, Chippaux J-P. Impact de la sensibilisation des populations dans la lutte contre la bilharziose urinaire au Niger. Cah Détudes Rech Francoph. 2001;11:35-42.

30. Biays S, Stich AHR, Odermatt P, Long C, Yersin C, Men C, et al. Foyer de bilharziose à Schistosoma mekongi redécouvert au Nord du Cambodge: I. Perception culturelle de la maladie; description et suivi de 20 cas cliniques graves. Tropical Med Int Health. 1999;4:662-73.

31. Gbalégba NGC, Silué KD, Ba O, Ba H, Tian-Bi NTY, Yapi GY, et al. Prevalence and seasonal transmission of Schistosoma haematobium infection among school-aged children in Kaedi town, southern Mauritania. Parasit Vectors. 2017;10:353.

32. Kloos H, Sidrak W, Michael AA, Mohareb EW, Higashi Gl. Disease concepts and treatment practices relating to schistosomiasis haematobium in upper Egypt. J Trop Med Hyg. 1982;85:99-107.

33. Sady H, Al-Mekhlafi HM, Atroosh WM, Al-Delaimy AK, Nasr NA, Dawaki S, et al. Knowledge, attitude, and practices towards schistosomiasis among rural population in Yemen. Parasit Vectors. 2015;8:436.

34. de Silva MA, Wijekoon A, Hornik R, Martines J. Care seeking in Sri Lanka: one possible explanation for low childhood mortality. Soc Sci Med. 2001;53:1363-72.

35. Odhiambo GO, Musuva RM, Atuncha VO, Mutete ET, Odiere MR, Onyango RO, et al. Low levels of awareness despite high prevalence of Schistosomiasis among communities in Nyalenda informal settlement, Kisumu City, western Kenya. PLoS Negl Trop Dis. 2014;8(4):e2784.

36. Anguza J, Oryema-Lalobo M, Oundo GB, Nuwaha F. Community perception of intestinal schistosomiasis in Busia district of Uganda. East Afr Med J. 2007; 84:56-66.

37. Schall VT. Health education, public information, and communication in schistosomiasis control in Brazil: a brief retrospective and perspectives. Mem Inst Oswaldo Cruz. 1995:90:229-34

38. Mandelzweig L, Goldbourt U, Boyko V, Tanne D. Perceptual, social, and behavioral factors associated with delays in seeking medical care in patients with symptoms of acute stroke. Stroke. 2006;37:1248-53.

39. Goldman N, Heuveline P. Health-seeking behaviour for child illness in Guatemala. Tropical Med Int Health. 2000;5:145-55.

40. Hill Z, Kendall C, Arthur P, Kirkwood B, Adjei E. Recognizing childhood illnesses and their traditional explanations: exploring options for careseeking interventions in the context of the $\mathrm{IMCl}$ strategy in rural Ghana. Tropical Med Int Health. 2003;8:668-76. 
41. Kloos H, Ouma JH, Kariuki HC, Butterworth AE. Coping with intestinal illness among the Kamba in Machakos, Kenya, and aspects of schistosomiasis control. Soc Sci Med. 1987;24:383-94.

42. Mackian S. A review of health seeking behaviour: problems and prospects HSD/WP/05/03: Manch Univ Manch Health Syst Dev Programme; 2003.

43. Yang G, Vounatsou P, Zhou X, Tanner M, Utzinger J. A potential impact of climate change and water resource development on the transmission of Schistosoma japonicum in China. Parassitologia. 2005;47:127-34.

44. Mwanga JR, Magnussen P, Mugashe CL, Gabone RM, Aagaard-Hansen J. Schistosomiasis-related perceptions, attitudes and treatment-seeking practices in Magu district, Tanzania: public health implications. J Biosoc Sci. 2004;36:63-81

Ready to submit your research? Choose BMC and benefit from:

- fast, convenient online submission

- thorough peer review by experienced researchers in your field

- rapid publication on acceptance

- support for research data, including large and complex data types

- gold Open Access which fosters wider collaboration and increased citations

- maximum visibility for your research: over $100 \mathrm{M}$ website views per year 